\title{
Transport Modelling During Preparation of General Plans in Big Cities: Reasons and Challenges
}

\author{
Paolo Beria ${ }^{1}$, Rasa Ušpalytè-Vitkūniene ${ }^{2}$ \\ ${ }^{1}$ Department of Architecture and Urban Studies, Milan Politecnico University, Milan, Italy \\ ${ }^{2}$ Urban Engineering department, Vilnius Gediminas Technical University, Vilnius, Lithuania \\ E-mails: 'Paolo.beria@polimi.it (correspondingauthor); ${ }^{2}$ rasa.uspalyte@vgtu.lt
}

\begin{abstract}
Rapidly growing mobility of people in European cities attaches greater importance to the sustainable development concept. The dynamics of European cities are however different. Cites such as Lithuanian, Slovakian and Polish ones will rapidly increase traffic flows and car ownership at fast pace. Also in most of Western Europe, even if at lower rates, private mobility is increasing. In some cities, however, car use and car ownership are finally decreasing, also thanks to policies implemented. Of course, an increase of traffic flows poses problems in terms of street space, pollution and liveability of cities. Sustainable integration of all kinds of transport into the urban development process is one of the most effective actions in the hands of city planners. The coordination between the planning of residential and business development areas and the expansion of public transport and its hierarchical integration is however a difficult but necessary exercise. Transport modelling tools, in particular, need important advancements to integrate transport and land use in simulations. This article analyses the main challenges in the use of transport models to support the construction of city plans by means of two case studies of Milan and Vilnius. The analysis deals both with traditional aspects, such as the proper simulation of multimodal choices, the level of detail of zoning, the issues associated to the simulation of traffic management policies. Then, we will focus on two aspects still open: the integration of transport modelling and economic assessment or ranking of actions, and the inclusion of land use changes in the modelling.
\end{abstract}

Keywords: urban transport, transport modelling, urban planning.

Conference topic: Sustainable urban development.

\section{Introduction}

The application of the principles of sustainable development requires a reliable knowledge of the current mobility and of the potential response of demand to transport policies, for example in terms of modal change.

Today, a number of software packages used for the modelling of the public transport have been created in the world. Some of them are the following: VISION, EMME/2, TRIPS, TRANSYT, CUBE usually used in European countries and America, and GETRAM and ASCII usually used in Asia. All of these programmes use a four stage integrated demand modelling, which covers traffic generation, distribution, choice of the mode of travel and path (Murray 2001; Duff-Riddelland, Bester 2005).

In a real city, trips of people are more complex than those in models due to the fact that more than one public transport (PT) mode exists and work in an integrate way. In 1994, Fernandez et al. proposed development of the integrated trip system with combined modes of trips at three levels: integrated trip modes, points of change and choice of route (Lo et al. 2004; Wardman 2001). At present, the proposed modes are used almost in all the models being used (Scenes, Litres-2, Expedite, Logit, Lohse, Kirchhoff, etc.) (Burinskienè et al. 2011).

Modelling of the city transport system involves to consider also city dynamics: population increases, the locations of the working places change according to economy evolution, industrial areas may decay, new attractors may appear, population moves to suburban areas. To reflect all these changes in the city, planners are constructing transport system models during the preparation of plans. The model should not only reproduce the current situation, but answer to the questions how the transport flows will regroup in the network after implementing some measures, how will modal split change after implementation of some prohibition measures or increasing quality/infrastructure, or of any other transport policy. Models could not answer to all questions, but could be good guide to the future transport system situation, if chosen presumptions are correct. In other words, the main question that should be answered is how the citizens will react to possible future transport networks. The most common questions to be answered by such applications, among others, are:

- locating closest facilities for a given location;

- finding the shortest routes between given locations;

- computation of the most efficient routes;

- defining service areas based on travel time or distance (Papšienè et al. 2014).

Some questions like changes of modal split could be derived from the experience of other countries, like analysing the European countries experience after restructuring or implementing of new kind of PT.

(C) 2017 Paolo Beria, Rasa Ušpalytė-Vitkūnienè. Published by VGTU Press. This is an open-access article distributed under the terms of the Creative Commons Attribution (CC BY-NC 4.0) License, which permits unrestricted use, distribution, and reproduction in any medium, provided the original author and source are credited. 


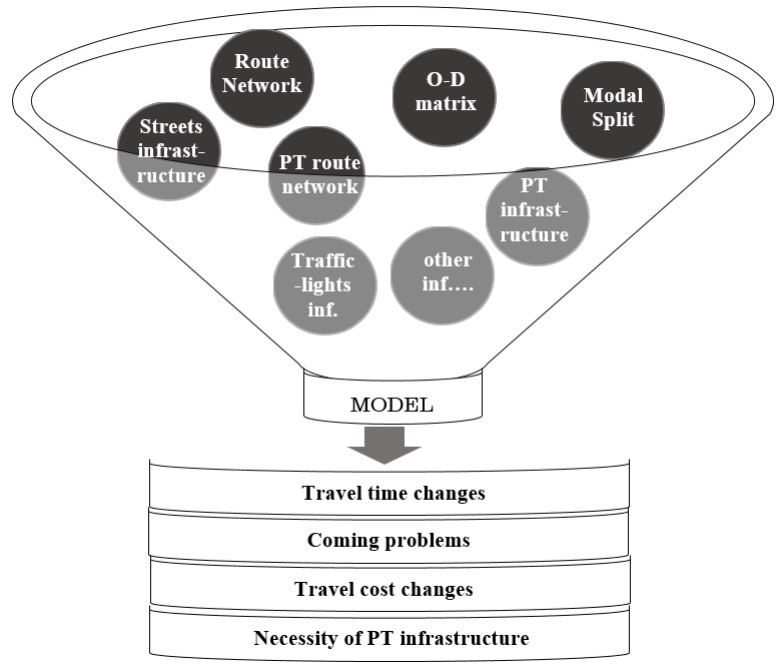

Fig. 1. Transport flows modelling consumption and benefits

Typically, transport models are largely data demanding. The information the model should receive (see Fig. 1) include the road and PT networks, origin and destination stops of the trips (except TSys-based method), duration of their trips among transport districts, load factors of the PT routes as calibration data, the number of transfers at stops and among transport modes, etc.

Modelling of the transport system allows analysis of different phenomena related to the traffic organisation without applying expensive practical experiments. Modelling is also the only way to forecast the need for transport in future and the behaviour of the system participants, as well as to plan actions for the implementation of the future scenarios.

\section{Modelling during plan}

Usually, during the high-level planning (called "special" or "general plan" in Lithuania and "strategic plan" in Italy), transport planners are developing several options for the future transport system development in the city. In order to compare the options, typically measuring the benefits for the city and residents, some criteria to rely on are needed. Transport models are the tool that can provide the indicators which makes it possible to compare different actions and evaluate each of them separately.

On the other side, the "mechanical" application of a model could not match well with decision-making process (and with the expectations of the decision-maker). Other elements, hardly controllable by simulations, might play an important role:

i. a land-use vision may prevail, whatever is the most efficient solution from the transport viewpoint;

ii. a set of alternatives could be predefined, because already in previous planning documents or because promoted by stakeholders;

iii. resources for the investment and for the running of public transport are typically limited, and projects must be chosen and ranked.

The recognition of a circular relation between transport, land-use and economy is a necessary condition of a realistic strategic planning exercise. Transport modelling alone is as a static picture, assuming the invariance of the other framework conditions (the mentioned territorial structure, the economy, demographics, etc.). Managing with a formalised model this complexity is an overwhelming task for most of cities, but the limitedness of a strict transport vision must be controlled during the process, at least by allowing feedbacks between land-use planners and transport planners, by introducing constraints ${ }^{1}$ and by accepting sub-optimal solutions for some criteria ${ }^{2}$. The challenge is thus to make transport modelling useful to decision-makers which do not necessarily base their decisions (only) on transport or economic criteria.

In the following we will briefly recall the main technical elements to be considered when modelling at the city scale. Then, we will introduce two cases, in Lithuania and Italy, of the use of transport models in the preparation of strategic city plans. Before conclusions, we will discuss two of the frontiers of use of transport models: to back socioeconomic assessment and as part of land use-transport integrated models (known as LUTI).

\footnotetext{
${ }^{1}$ For example, high residential densities might be necessary because of insufficiency of stock, even if imposing an excessive load on road networks and thus needing further public expenditure to expand otherwise unnecessary networks.

2 An economically optimal solution for the transport system might not be such if considering also other domains of decision, like land preservation.
} 

and challenges

\section{Model setting}

Models require a careful and expensive preparation, involving a choice on many elements. Here we discuss some of them, with particular focus on urban problems.

Time period. The transport network of the city is periodically overloaded (see Fig.2). This takes place during morning and afternoon rush hours when the main problems of transport network or public transport become vivid. Thus, the need for changes during rush hours is most relevant and usually chosen as the time interval for the modelling. As often indicators refer to a daily or yearly base (e.g. passengers per year of a new metro line), expansion factors determined empirically are often used. Despite practical and broadly used, they might introduce biases, for example when ignoring the non-linearity of congestion: the congestion-relief effect of a new metro line during peak hour could be more than proportional to the same effect during off-peak, when roads are emptier and congestion even not existing.

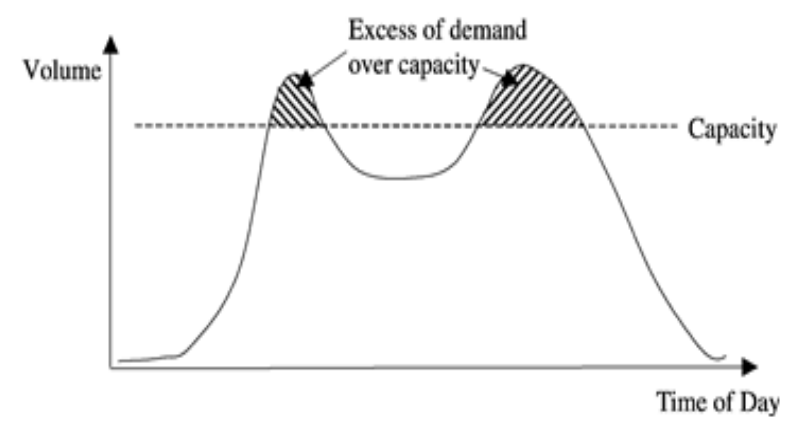

Fig. 2. Traffic/passengers in PT flow changes during the day-time

Boundaries and zoning. The setting of model boundaries is one of the first operations and heavily influencing both the cost of the model and its reliability. Typically, the larger the study area, the higher the effort and the data needed. To the contrary, a too limited study area may omit important border effects, or lose details such as the points of entry of traffic flows from city outskirts. In general, the study area ends with the end of the relevant effects of the projects and actions that the model is going to simulate, but also administrative boundaries might count.

A second and related aspect is zoning. Also in this case there is a clear trade-off between modelling effort and richness of detail. In addition, zones dimension is linked also to the availability of data: small zones might be needed for a problem, but census and O/D (original-destination) data might not be available at such detail. For example, in Milan's transport model (described later) the dimension of the zones increase with distance from centre, because less detail is needed. At the same time, even if policies are implemented at the city scale, their effects spread far from the municipal boundaries and the modelled area must be sufficiently large.

Calibration. The preliminary step before modelling theoretical variants of transport systems is to calibrate the existing public transport model to evaluate the compliance of the data collected when investigating passenger flows. Calibration of the model requires the selection of such parameters that model results as much as possible reflect the reality. On this calibration we can refer to the Correlation coefficient $r$ to show the relation of one of the factors $y$ (model's generated passenger flows) with another variable $x$ (passenger flows registered during investigation) and at the same time to evaluate how the constructed model of the transport system fits the functioning of the real transport system. More reliable is the Determination coefficient, a number that indicates the proportion of the variance in the dependent variable that is predictable from the independent variable. The parameter describing the quality of the statistics, the well-known Determination coefficient. $R^{2}=1$ means that the modelled values ideally match a set of observations. The determination coefficient being closer to zero, the more the predicted values differ from observed values. The determination coefficient indicates the percentage of modelled values linearly dependent on the value of observation. A sufficiently reliable model could have $\mathrm{R}^{2} \geqslant 0.7$. If this coefficient is lower, the model should be significantly reconsidered.

The accuracy of the model is also described in other sizes - RMSE (Eng. Root Mean Squared Error), which shows how much modelled values different from the observed values.

Programming package usually automatically draw the graph, which shows a linear regression to re-curve and the coordinate plane and out the simulated tests set value (see Fig. 3). During calibration, try to adapt the model parameters so that the simulated values as much as possible in parallel to the observation and the regression curve is inclined at an angle of 45 degrees.

One of the key indicators for public transport model calibration is a general indicator of passenger transfers, which could be taken from research on public transport passenger flows. A very high indicator of transfers shows has a negative impact on the choice of public transport for travelling. To verify the model, points were chosen that gave the best illustration of passenger distribution on the network. These are groups of stops, usually used for transfer from one transport mode to another and the cross-section of the streets with the highest load during morning rush-hours. 


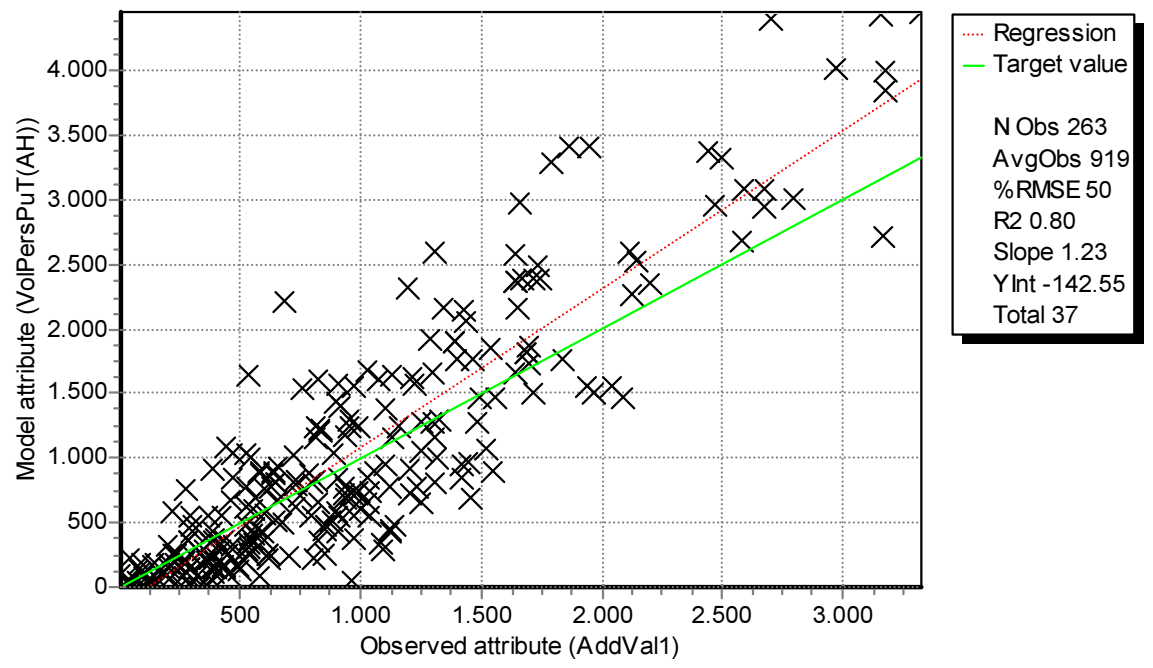

Fig. 3. Correlation between the current passenger flow and generated by model

The obtained results, i.e. the number of passengers at the stops and street sections in question, are interpreted as a coefficient revealing their correspondence to the basic data, which revealed the percentage of correspondence of the obtained numbers to the real passenger flow survey's data.

\section{Modelling during planning process in Lithuania}

Modelling of transport system during the planning has been used very recently in Lithuania. There were only three projects which modelled all the urban transport system. They where: Kaunas public transport project (2005-2006), Master plan of Kaunas city (2012-2013) and Special plan for the Selection of New Kind of the Public transport for the city of Vilnius (2011-2013) (Burinskienè et al. 2012). It was acknowledged that modelling would have prolonged the time of planning and would have risen the cost by 30-40 percent. Lithuanian municipalities usually refused modelling because of lack of funds. At present time, the situation is changing little by little and in nowadays Sustainable Urban Mobility Plans at least three municipalities included modelling as a mandatory part of these plans.

Therefore, strategically the most important current aim of the communication system is to change the trends of the city transport system development. Pragmatically, measures and methods guaranteeing the redistribution of mobility for the benefit of pedestrians, cyclists and public transport are required. A balanced communication system of a city is impossible without analogous sustainable and regulated urban development.

The following strengthening methods of PT market are proposed:

$\checkmark$ Giving priorities and supporting them by financial loans, it is necessary to increase the development density in the central part of the city and the main communication system corridors axes.

$\checkmark \quad$ To regulate the parking process of cars, by introducing new compulsory specialized parking standards, tightening the parking policy and limiting access to the city centre by cars.

$\checkmark \quad$ To target all monetary resources towards the implementation of a comprehensive public transport reorganization strategy through the introduction of a NPTM during the construction period by limiting the construction of the main streets without PT and using parking fees and car user charges for the development of public transport (Grigonis et al. 2014).

Therefore, the communication system shall be diversified, providing an option for a user to choose various types of PT modes, their capacity, service type, communication speed, uniform or combined communication system. The development of the communication system is the principle of gradual evolution, correlating with real needs and possibilities, which show that the existing public transportation system with the existing transport modes is not capable of competing with the prevalence of cars in the common system of travelling, although their carrying capacity is capable of that. It is concluded that major shift in government policy needed to change the trends of the car users and declining PT passenger's flows (Attard, Hall 2003; Nahuis 2011; Pflieger et al. 2009). Measures reliability for the solving these problems could be founded and substantiate during the modelling process.

The models of Vilnius and Kaunas cities in all three plans where constructed in the most reliable way possible. The determination coefficient varied between 0.77 in Kaunas till 0.82 in Vilnius. The 3 years after modelling of Vilnius public transport system could be seen effect of first modelled step - implementation of fast buses routs in the network. If to compare public transport passengers flows to the model ones the reliability of the model was more than 80 percent and taking into account that where some changes in proposed fast buses rout network. 
An example of planning application in Italy: the economic evaluation of Milan's Sustainable Urban Mobility Plan (SUMP)

The diffusion of transport modelling in Italy is far from homogeneous. Some of the larger cities use models to support their plans or their transport projects. However, these models are often not in-house by the administrations, but supplied on demand by consultants and consequently not maintained for periodical use. Few cities manage the process with internal staff, such as Milan, while other buy commercial software, set up models with the help of external experts and eventually maintain them for continuous use.

City level is not the only relevant one. As extra urban bus networks are managed and planned by the Provincial governments, cities do not control over part of the bus network that cross and serve their territory on a larger scale. Similarly, all regional rail services are under the rule of Regional governments, which in turn must prepare their plans and decide for their investments.

In terms of diffusion of models, most of cities use these tools for decisions. At the regional scale models are less used (they often rely on rail operator's inputs), with some relevant exceptions in major regions such as Lombardy, Emilia Romagna, Tuscany and Campania which manage hundreds of millions Euro of service contracts.

Among the most recent applications, the Milan 2015-2025 sustainable urban mobility plan (SUMP) is one of the first examples of a transport model, which has been used jointly with socio-economic assessment tools to support the decision process of the city plan (Beria, Grimaldi 2014).

The four-step model is developed with a commercial software and models Milan plus 40 surrounding municipalities, but considers the demand originated and directed to/from 200 further municipalities. The modal split module has cost functions considering travel time, frequency, interchanges and fares for public transport; running costs, parking fares, congestion charging and travel time (with congestion) for private transport. The model results particularly complex because of the complexity and extension of the study area, but also because it allows modelling the road pricing and the park pricing policies in place in the area (Beria 2016).

For the first time in Italy, the plan included a socio-economic assessment through Cost Benefit Analysis of the projects already at the strategic stage and not later, when actions were already defined. For this reason, the plan and the assessment procedure took place early during the plan definition and considered a broad number of alternatives. In particular, a pre-selection phase generated 51 explorative scenarios, each one made of one single action. The nature of these actions is very heterogeneous, ranging from large infrastructural investments to existing lines extension, to the reorganisation of services. The socio-economic assessment reduced the worthwhile actions to 17 and all of these were included in the Plan scenario, which underwent a further assessment to point out possible synergies among actions.

The evaluation process was totally integrated with the transport model, according to the scheme in Fig. 4.

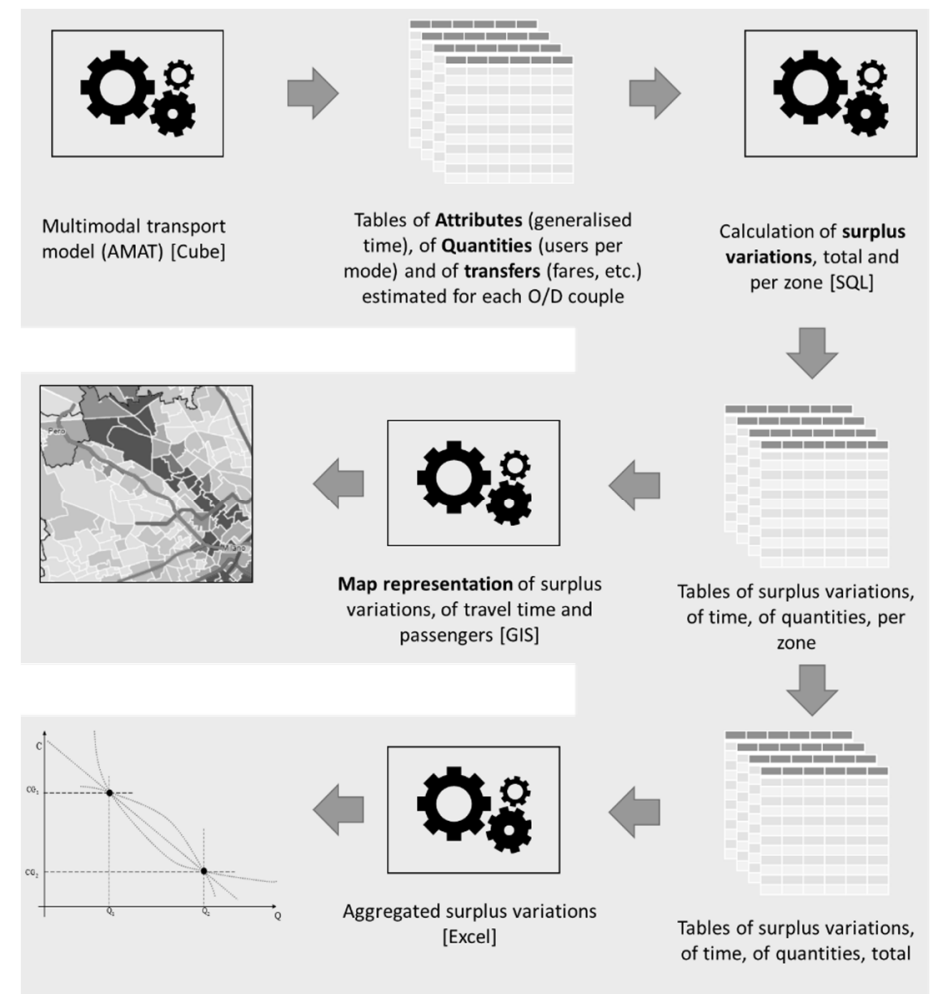

Fig. 4. The model-integrated assessment procedure implemented for the Milan's sustainable urban mobility plan (SUMP). Source: Comune di Milano (2015). 

and challenges

In particular, from the transport model we obtained (Beria, Grimaldi 2014) the utilities and the calibration parameters, guaranteeing a complete consistency between the model and the following cost-benefit analysis. More precisely, from systematic utilities Cascetta (1998) used by the model, divided by the $\beta^{\text {time }}$, we obtained the generalised time, then multiplied by the Values of (in-vehicle) Time (VoT), to obtain the generalised cost. This has been done to overcome the fact that some modes (cycling, walking) did not have any monetary component of utility, making impossible the direct conversion to the generalised cost. This method can be used (see for example Castiglione et al., 2003, or de Jong et al. 2007), but loses some consistency between model and assessment.

When the GCs are estimated, we applied a double methodology to estimate the consumers' surplus variation: the Rule of Half and the logsum method (for details see Beria and Grimaldi 2014). It must be noticed that this passage is done at the highest level of disaggregation: per origin - destination pair $(O / D)$, travel purpose $(s)$ and mode $(m)$. This computational burden, involving even millions of operations, allowed a successive regrouping of the results as needed, for example producing consumers' surplus variations maps.

\section{Towards land use transport interaction models}

From the theoretical point of view, transport models are a mature tool, available commercially and whose main limit to application is the cost and complexity of their management.

To date, one of the frontiers of these applications lays in the inclusion of the land use components among the elements modelled. It is clear, in fact, that the description of transport system alone, even if sophisticated, may miss some key drivers of mobility, such as the choice of the location of residences and of attractors. While land use is considered in the generation and distribution models, there is no feedback from transport simulations to the locational choices. In other words, the land use is usually exogenous for the models, while in reality land use depends also on accessibility.

There are however a number of studies and applications that include, with various levels of complexity, land use choices into the transport models and thus allow to simulate both what happens to mobility due to changes into the land use, and how land use changes due to transport costs. For a broad review of these models, called LUTI (Land use transport interactions), refer to the recent work of Acheampong and Silva (2016).

Among the most interesting applications, Börjesson et al. (2014a) through the assessment of six large urban projects in Stockholm with and without considering the land use elasticity, find that the impacts of land-use choices into transport system are large, while the capability of transport to change the land-use exists but is much more limited. Similar findings were found by van Wee and Maat (2003), who however attributed them to limits of the models. Börjesson et al. (2014b), with the same model, can simulate how Stockholm would have looked like if the metro were not built. In particular, the Swedish capital would have been much more compact and miles driven slightly lower. In fact, the presence of a metro has increased largely the use of car for non-work trips and has allowed citizens to locate farther from city centre. This apparently counterintuitive result shows that are the planning rules that make a city compact or sparse, and the transport supply can influence it just slightly.

The study called Solutions (Echenique et al. 2010, 2012), uses a LUTI model to study the effect of different urban planning strategies in the UK. They show how the current rules, limiting the expansion of London by the Green Belt have risen house prices and pushed residences far away, increasing miles travelled and giving just a small reduction in energy consumption with respect to a sprawled asset. Allowing a controlled expansion of the city would instead give the benefit of lowering prices and increasing housing options, but without an increase in the car use.

The model MARS (Wang et al. 2015) is based on a conventional transport model linked to land-use submodels (residential location and workplace location). The models are linked through measures of potential accessibility. MARS is used to test two policy scenarios in Marid, both designed to reduce car use with respect to the base scenario: a cordon toll scenario and a combination of cordon toll and higher bus frequency. The effect of the policies is measured also in terms of effect on job location, allowing more informed planning decisions.

Out of Europe, Waddel et al. (2007) develop a model called UrbanSim to simulate both locational, employment and mobility choices. All submodels use logit to calculate the probability of agents (households, workers and firms) to locate and move in a certain way. In this way they also introduce land price, which is a key driver of all of such choices.

The limits of these models lay in their complexity, in the difficulty to calibrate them but also in the limitedness of predicting nonlinear changes to mobility and locational choices. Van Wee (2016) calls for a new generation of models capable to explain phenomena such as peak car, decline in population, change in shopping practices, different ways of work and soft mobility. These facts are increasingly important and increasingly capable to modify people's mobility and land use.

\section{Conclusions}

The use of transport models is increasingly common, even in countries with weaker planning traditions, being the only way to cope with the complexity of the mobility in large urban contexts. More and more they will be useful if capable to simulate also the effect of non-infrastructural policies, such as road pricing, bike lanes, traffic limitations, etc. 

and challenges

The two cases presented describe two similar applications of transport models to urban mobility planning, in coherency with the most recent European guidelines on SUMPs. Both cases show how models can evaluate noninfrastructural policies, such as park pricing, road pricing and other soft measures. Models can also be usefully interfaced with the assessment phase, to feed cost benefit analysis and ultimately to help the decision process both on the transport and on the economic sides.

Most advanced tools acknowledge also the feedbacks that exist between mobility choices and land-use choices, by means of accessibility measures and by introducing the land price into modelling. These tools are much more effective for long run structural plans, where the attractors and generators locations cannot be treated as purely exogenous and constant.

\section{Acknowledgements}

Paolo Beria wishes to thank Raffaele Grimaldi, which contributed significantly to the project of Milan SUMP. Similarly, our thanks go to Luca Tosi, Giorgio Dahò, Patrizia Malgieri, Alfredo Drufuca and Maria Berrini for their support during the process and for having believed in this tool.

\section{References}

Acheampong, R.; Silva, E. 2016. Land use-transport interaction modeling: a review of the literature and future research directions, Journal of Transport and Land Use 8(3): 11-38.

Attard, M.; Hall, D. 2003. Public transport modernisation and adjustment to EU accession requirements: the case of Malta's buses, Journal of Transport Geography 11: 13-24. https://doi.org/10.1016/S0966-6923(02)00045-5

Beria, P.; Grimaldi, R. 2014. Cost Benefit Analysis to assess urban mobility plans. Consumers' surplus calculation and integration with transport models. Munich Personal RePEc Archive. [online], [cited 03 July 2017]. Available from Internet: http://mpra.ub.uni-muenchen.de/59590/

Beria, P. 2016. Effectiveness and monetary impact of Milan's road charge, one year after implementation, International Journal of Sustainable Transportation 10(7): 657-669. https://doi.org/10.1080/15568318.2015.1083638

Börjesson, M.; Jonsson, R. D.; Berglund, S.; Almström, P. 2014a. Land-use impacts in transport appraisal, Research in Transportation Economics 47: 82-91. https://doi.org/10.1016/j.retrec.2014.09.021

Börjesson, M.; Jonsson, R. D.; Lundberg, M. 2014b. An ex-post CBA for the Stockholm Metro, Transportation Research Part A: Policy and Practice 70: 135-148. https://doi.org/10.1016/j.tra.2014.10.006

Burinskienė, M.; Grigonis, V.; Ušpalytė-Vitkūnienė, R. 2012. Trends of public transport development in Vilnius: passengers flows simulation and economical feasibility, in 2012 International Conference on Electronics, Information and Communication Engineering (EICE 2012), 1-2 March 2012, Macau, China.

Burinskienė, M.; Tuminienè, F.; Ušpalytė-Vitkūnienė, R. 2011. Public transport integration into urban planning, The Baltic Journal Of Road And Bridge Engineering 6(2): 84-90. https://doi.org/10.3846/bjrbe.2011.11

Cascetta, E. 1998. Teoria e Metodi della ingegneria dei sistemi di trasporto. UTET, Torino (Italy).

Castiglione, J.; Freedman, J.; Davidson, W. 2003. Application of a tour-based microsimulation model to a major transit investment. San Francisco County Transportation Authority and PBConsult, San Francisco.

Comune di Milano. 2015. Piano urbano della Mobilità Sostenibile 2015-2025. Documento di Piano. Allegato 1 - Analisi CostiBenefici socioeconomica e finanziaria. AMAT, Milano, Italy

De Jong, G.; Daly, A.; Pieters, M.; Van der Hoorn, T. 2007. The logsum as an evaluation measure: review of the literature and new results, Transportation Research Part A: Policy and Practice 41(9): 874-889. https://doi.org/10.1016/j.tra.2006.10.002

Duff-Riddelland, W. R.; Bester, C. J. 2005. Network modelling approach to transit network design, Journal of Urban Planning and Development 131(2): 87-97. https://doi.org/10.1061/(ASCE)0733-9488(2005)131:2(87)

Echenique, M. H.; Hargreaves, A. J.; Mitchell, G.; Namdeo, A. 2012. Growing cities sustainably: does urban form really matter?, Journal of the American Planning Association 78(2): 121-137. https://doi.org/10.1080/01944363.2012.666731

Echenique, M.; Barton, H.; Hargreaves, T.; Mitchell, G. 2010. SOLUTIONS - Sustainability of Land Use and Transport in Outer Neighbourhoods. Final Report.

Grigonis, V.; Burinskienė, M.; Paliulis, G. M.; Ušpalytė-Vitkūnienė, R.; Dumbliauskas, V.; Barauskas, A. 2014. Modelling a passenger car system based on the principles of sustainable mobility in Vilnius City, Transport 29(3): $334-341$. https://doi.org/10.3846/16484142.2014.953998

Lo, H. K.; Yip, C. W.; Wan, Q. K. 2004. Modelling competitive multi-modal transit services: a nested logit approach, Transportation Research Part C 12C: 251-272. https://doi.org/10.1016/j.trc.2004.07.011

Murray, A. T. 2001. Strategic analysis of public transport coverage, Socio-Economic Planning Sciences 35: $175-188$. https://doi.org/10.1016/S0038-0121(01)00004-0

Nahuis, R. 2011. The distribution of decision making: the case of a flexible public transport system, Administration \& Society 43(3): 319-345. https://doi.org/10.1177/0095399711400045

Papšienė, P.; Balčiūnas, A.; Beconytė, G.; Motiejauskas, D.; Romanovas, D.; Aksamitauskas, V. Č.; Papšys, K. 2014. Feasibility of integrated transport network model in Lithuania, Transport 29(4) 346-354. https://doi.org/10.3846/16484142.2014.982175 
Beria, P.; Ušpalytè-Vitkūnienè, R. 2017. Transport modelling during preparation of general plans in big cities: reasons and challenges

Pflieger, G.; Kaufmann, V.; Pattaroni, L.; Jemelin, C. 2009. How Does Urban Public Transport Change Cities?, Urban Studies 46(7): 1421-1437. https://doi.org/10.1177/0042098009104572

Van Wee, B. 2016. Viewpoint: toward a new generation of land use transport interaction models, Journal of Transport and Land Use 8(3): 1-10.

Van Wee, B.; Maat, K. 2003. Land-use and transport: a review and discussion of Dutch research, European Journal of Transport Infrastructure Research 3(2): 199-218.

Waddell, P.; Ulfarsson, G.; Franklin, J.; Lobb, J. 2007. Incorporating land use in metropolitan transportation planning, Transportation Research Part A 41: 382-410. https://doi.org/10.1016/j.tra.2006.09.008

Wang, Y.; Monzon, A.; Di Ciommo, F. 2015. Assessing the accessibility impact of transport policy by a land-use and transport interaction model - the case of Madrid, Computers, Environment and Urban Systems 49: 126-135. https://doi.org/10.1016/j.compenvurbsys.2014.03.005

Wardman, M. 2001. Public transport values of time, Transport Policy 11: 363-377. https://doi.org/10.1016/j.tranpol.2004.05.001 